\title{
Statistical analysis of post mortem DNA damage-derived miscoding lesions in Neandertal mitochondrial DNA Sergi Vives ${ }^{1,2}$, M Thomas Gilbert ${ }^{3}$, Conchita Arenas ${ }^{1}$, Elena Gigli4 ${ }^{4}$ Oscar Lao $^{5}$ and Carles Lalueza-Fox*4
}

\begin{abstract}
Address: ${ }^{1}$ Departament d'Estadística, Facultat de Biologia, Universitat de Barcelona, Avda. Diagonal 645, 08028 Barcelona, Spain, ${ }^{2}$ Statistics Department, Columbia University, 1255 Amsterdam Avenue, New York, NY 10027, USA, 32Department of Biology, Center for Ancient Genetics, Universitetsparken 15, DK-2100 Copenhagen Ø, Denmark, ${ }^{4}$ Institut de Biologia Evolutiva (CSIC-UPF), Dr. Aiguader 88, 08003 Barcelona, Spain and ${ }^{5}$ Department of Forensic Molecular Biology, Erasmus Medical Center Rotterdam, Rotterdam, The Netherlands

Email: Sergi Vives - svives@stat.columbia.edu; M Thomas Gilbert - mtpgilbert@gmail.com; Conchita Arenas - carenas@ub.edu; Elena Gigli - giglielena@yahoo.it; Oscar Lao - o.laogrueso@erasmusmc.nl; Carles Lalueza-Fox* - carles.lalueza@upf.edu

* Corresponding author
\end{abstract}

Published: 10 July 2008

BMC Research Notes 2008, 1:40 doi:10.1 I86/1756-0500-1-40
Received: 30 April 2008

Accepted: 10 July 2008

This article is available from: http://www.biomedcentral.com/1756-0500/I/40

(c) 2008 Vives et al; licensee BioMed Central Ltd.

This is an Open Access article distributed under the terms of the Creative Commons Attribution License (http://creativecommons.org/licenses/by/2.0), which permits unrestricted use, distribution, and reproduction in any medium, provided the original work is properly cited.

\begin{abstract}
Background: We have analysed the distribution of post mortem DNA damage derived miscoding lesions from the datasets of seven published Neandertal specimens that have extensive cloned sequence coverage over the mitochondrial DNA (mtDNA) hypervariable region I (HVSI). The analysis was restricted to $C \rightarrow T$ and $G \rightarrow A$ miscoding lesions (the predominant manifestation of post mortem damage) that are seen at a frequency of more than one clone among sequences from a single PCR, but do not represent the true endogenous sequence.

Findings: The data indicates an extreme bias towards $C \rightarrow T$ over $G \rightarrow A$ miscoding lesions (observed ratio of 67:2 compared to an expected ratio of 7:2), implying that the mtDNA Light strand molecule suffers proportionally more damage-derived miscoding lesions than the Heavy strand.

Conclusion: The clustering of $\mathrm{Cs}$ in the Light strand as opposed to the singleton pattern of $\mathrm{Cs}$ in the Heavy strand could explain the observed bias, a phenomenon that could be further tested with non-PCR based approaches. The characterization of the HVSI hotspots will be of use to future Neandertal mtDNA studies, with specific regards to assessing the authenticity of new positions previously unknown to be polymorphic.
\end{abstract}

\section{Findings}

The retrieval of DNA from extinct humans such as Neandertals is technically challenged by problems associated with post mortem damage of the original DNA [1]. The growing availability of Neandertal mitochondrial DNA (mtDNA) hypervariable (HVS) sequences (predominantly HVS1), generated with the polymerase chain reac- tion (PCR) provides a novel dataset to study miscoding lesions associated to DNA damage.

The identification of true post mortem damage-derived miscoding lesions in ancient DNA studies, and their discrimination from other PCR artifacts, has been subject of much debate. Although the predominant cause was origi- 
nally argued to be due to cytosine deamination, generating $\mathrm{C} \rightarrow \mathrm{T}$ and $\mathrm{G} \rightarrow \mathrm{A}$ miscoding lesions in the retrieved sequences $[2,3]$, a number of studies that examined additional datasets suggested that damage may also include adenine to hypoxanthine modifications, thus resulting in $\mathrm{A} \rightarrow \mathrm{G}$ and $\mathrm{T} \rightarrow \mathrm{C}$ miscoding lesions $[4,5]$. The advent of 454/FLX sequencing technology, that allows the identification of which single DNA strand has been sequenced, has helped resolve this debate. In agreement with the original hypotheses $[2,3]$, it is now generally accepted that cytosine deamination is the sole cause of damage-derived miscoding lesions, observed as $\mathrm{C} \rightarrow \mathrm{T}$ or $\mathrm{G} \rightarrow \mathrm{A}$ miscoding lesions [6-9].

We have investigated the distribution of post mortem damage-derived $\mathrm{C} \rightarrow \mathrm{T}$ and $\mathrm{G} \rightarrow \mathrm{A}$ miscoding lesions in a dataset of Neanderthal HVS1 cloned PCR products. To discriminate between true damage and other PCR artifacts, we took into account only those mutations that are observed as 'consistent' within the datasets, i.e., those base modifications that are observed at a frequency $>1$ within sequences of a single PCR, but do not represent the consensus sequence as determined through the analysis of multiple independent PCRs of the region [3]. We note that it cannot be assumed, that all the $\mathrm{C} \rightarrow \mathrm{T}$ and $\mathrm{G} \rightarrow \mathrm{A}$ changes are authentic miscoding lesions, and our analysis likely overestimates the true level as some $\mathrm{C} \rightarrow \mathrm{T}$ and $\mathrm{G} \rightarrow \mathrm{A}$ changes might be PCR-generated artifacts $[9,10]$.

To exclude other potential biases that might affect the findings, the analysis was furthermore limited to Neandertal sequences that contained the complete Neandertal motif for the amplicon. In this way we were able to exclude contaminant AMH sequences, Neandertal-AMH hybrid sequences, or other artifacts that might derive from jumping-PCR/PCR recombination. As a result of these criteria, the data represents a conservative estimate of the true damage. The goal of the present study is to characterize the different DNA miscoding lesions detected in Neandertals in relation to each specific strand and also to the nucleotide composition. We have also investigated whether the damage is randomly distributed along the HVS1 region, or if there are specific nucleotide positions (sites) that exhibit above expected levels of DNA mutations (termed here hotspots). If such miscoding lesion hotspots do exist in the Neandertal HVS1 region, then it would be useful to identify them for future Neandertal mtDNA studies, with specific regards to the authentication of new positions previously unknown to be polymorphic in Neandertals.

\section{Methods}

The cloned sequences from the HVS1 fragment of the mitochondrial DNA (mtDNA) of the seven Neandertal specimens that exist with extensive (>300 nucleotides) coverage were used in the analysis. These include: Feldhofer 1 and 2 from Germany [11,12], Mezmaiskaya from Russia [13], Vindija 80 from Croatia [14], Monti Lessini from Italy [15], El Sidrón 1252 from Spain [16] and Okladnikov from Russia [17].

For all datasets the statistical analyses were performed on the cloned sequences between nucleotide positions 16056-16375, with reference to the Cambridge Reference Sequence (CRS) [18]. To account for biases in the numbers of PCRs that the different datasets themselves, and different positions within each dataset, had undergone, the frequencies of the observed mutations were weighted by the number of the examined PCR at that position following [4]. For full data see Additional files 1, 2 and 3.

\section{Identification of hotspots}

The identification of post mortem damage derived hotspots in previous studies $[19,20]$ was through statistical comparison of the actual observed distribution against that predicted under a hypothesis of random distribution. This approach was not taken in this study due to limitations on the current Neandertal dataset (the frequency of multiple mutations takes only values 0,1 and 2, thus a simple test of goodness of fit to a Poisson distribution of the observed pattern of mutations can not be performed). Moreover, in the previous analyses the position of the mutation itself is not considered, which is desirable if the hotspots themselves are to be identified. We adopted an alternative statistical procedure that enabled us to identify specific sites of above-expected mutation rate.

To establish the identity of hotspots, we initially collated the genetic information from all seven Neanderthal individuals into a single consensus individual that includes all these positions that are not polymorphic among them. Against each position in the consensus we subsequently scored the sum total number of damage-derived mutations observed (identified as described above) and the sum total number of PCRs performed over that nucleotide (see Additional file 4). The initial analytical requirement for analyzing the hotspots was the partitioning of the complete analyzed sequence into an equal number of bins. Adopting Sturges' rule, we therefore collapsed the 320 nucleotide sites of the alignment into 8 discreet bins containing 40 successive positions each. The expected probability of multiple mutation (per position) can therefore be calculated as $p=\frac{1}{8} \frac{\alpha}{\beta}$, where $\alpha$ is the total number of multiple mutations in the all region (positions 56 - 375) and $\beta$ is the total number of examined PCR in the all region (positions 56 - 375). From these probabilities we obtained the expected frequencies (see Table 1) of multi- 
Table I: Summary data including observed and expected number of consistent mutations observed over the discrete HVS I region analysed considering a Neandertal consensus sequence.

\begin{tabular}{|c|c|c|c|c|c|c|c|c|c|}
\hline & \multicolumn{9}{|c|}{ Region } \\
\hline & 1 & 2 & 3 & 4 & 5 & 6 & 7 & 8 & \\
\hline & \multicolumn{9}{|c|}{ Positions (16---) } \\
\hline & $56-95$ & $96-135$ & $136-175$ & $\mid 76-215$ & $216-255$ & $256-295$ & $296-335$ & $336-375$ & \\
\hline Neandertal consensus HVSI & & & & & & & & & Total \\
\hline Consistent mutations & 9 & 10 & 13 & 16 & 10 & 19 & 1 & 7 & 85 \\
\hline PCR & 667 & 597 & 655 & 734 & 957 & 724 & 666 & 583 & 5583 \\
\hline Expected mutations & 1.269 & 1.136 & 1.246 & 1.397 & 1.821 & 1.378 & 1.267 & 1.109 & \\
\hline
\end{tabular}

PCR refers to the number of independent cloned PCR reactions over the region.

ple mutations per region according to the following expression: $f_{i}=p n_{i}$, where $n_{i}$ is the total number of examined PCR in region $i(i=1, \ldots, 8)$. For detailed justification of the method refer to supplementary information.

\section{Results and Discussion}

The nucleotide composition of the consensus Neandertal mtDNA sequence is shown in Table 2. Also indicated is the number of nucleotide positions within the dataset that are observed to contain consistent miscoding lesions of any type (i.e. prior to selection for data analysis). For the complete list of the nucleotide composition of the miscoding lesions, see Additional file 3 .

The fraction of the total $\mathrm{C}$ nucleotide positions that are observed to contain sequencing errors $(63.55 \%)$ is much higher than those of $\mathrm{A}, \mathrm{G}$ and $\mathrm{T}(9.09 \%, 6.45 \%$ and $6.94 \%$, respectively). Of the cytosine mutations themselves, $98.5 \%$ represent $\mathrm{C} \rightarrow \mathrm{T}$ changes, while the only two consistent sequence modifications detected in positions containing $\mathrm{G}$ nucleotides are $\mathrm{G} \rightarrow \mathrm{A}$ changes. In light of current understandings of DNA damage, this observation of a heavy bias towards C damage is extremely odd. Due to the complementary nature of the DNA molecule, any $\mathrm{C} \rightarrow$ T modification on a particular DNA strand within the double helix (say the mtDNA Light strand) will be manifested after PCR amplification and sequencing as either a $\mathrm{C} \rightarrow \mathrm{T}$ miscoding lesion on the descendent Light strand

Table 2: Consistent miscoding lesions observed among the dataset.

\begin{tabular}{llllll}
\hline & A & C & G & T & \\
\hline A & 100 & & 8 & 2 & 110 \\
C & 1 & 39 & & 67 & 107 \\
G & 2 & & 29 & & 31 \\
T & & 5 & & 67 & 72 \\
& 103 & 44 & 37 & 136 & 320
\end{tabular}

Vertical: original nucleotide composition; Horizontal: observed nucleotide changes. molecules, or as the complementary $\mathrm{G} \rightarrow \mathrm{A}$ miscoding event on the complementary strands (in this example the mtDNA Heavy strand) [21]. In contrast, any $\mathrm{C} \rightarrow \mathrm{T}$ damage event on a Heavy strand molecule will lead to either a $\mathrm{C} \rightarrow \mathrm{T}$ modification on descendent Heavy strand molecules, or $\mathrm{G} \rightarrow \mathrm{A}$ mutations on descendent Light strand molecules. As $\mathrm{C} \rightarrow \mathrm{T}$ mutations form the only credible source of DNA damage-derived miscoding lesions $[8,9]$, a consequence of this argument is as follows. If $\mathrm{C} \rightarrow \mathrm{T}$ DNA damage occurs with equal probability on both Heavy and Light strand template molecules, at a frequency that is only dependent on the strands' base compositions, then the damage should be manifested as observations of both $\mathrm{C} \rightarrow \mathrm{T}$ and $\mathrm{G} \rightarrow \mathrm{A}$ sequence modifications within cloned Light strand descendent sequences, at a frequency dependent on the base composition. It is with this regard that the 7 Neandertal sequences appear striking - the observed ratio of $\mathrm{C} \rightarrow \mathrm{T}: \mathrm{G} \rightarrow \mathrm{A}$ consistent sequence modifications is $67: 2$, a marked deviation from the approximate 3.5:1 that would be expected under the hypothesis of equal likelihood of DNA damage per different template strand (calculated as the ratio of cytosines on the Light strand:cytosines on the Heavy strand in Table 2). The implication therefore, is either that the Light strand molecule is subject to proportionally more damage-derived miscoding lesions than the Heavy strand molecule in the Neandertal datasets, or the 7 Neandertal datasets, all derived using different means by different researchers in different laboratories, all suffer from a common form of methodological bias or weakness.

These observations are not without precedent. In a previous study on aDNA damage [19] an apparent bias of original mtDNA Light strand template molecules was observed among the data, although this could not be supported by statistical analysis. The same study also provided evidence that the Heavy strand might be subjected to increased rates of DNA degradation or damage (with respect to the Light strand) in such a way that limits PCR amplification. These observations would seem to be sup- 


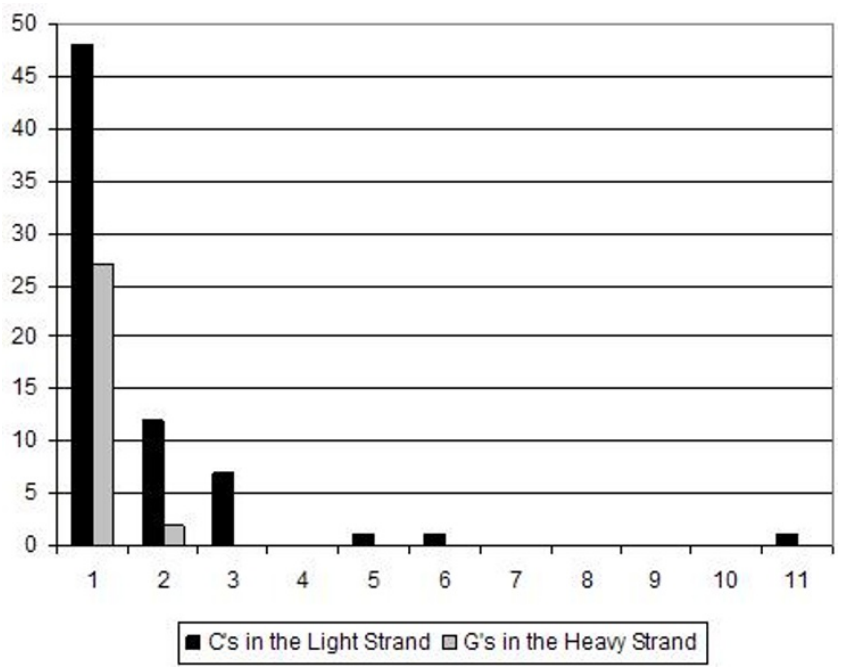

Figure I

Differential clustering (from singletons to II repeats) of cytosines on the mitochondrial Light Strand and guanines on the Heavy Strand of the Neandertal sequences (the 16054056 and 16375-380 clusters extend beyond the 1605516375 studied region).

ported by the data observed here. While the potential cause of this is difficult to ascertain, one possible reason might be that the high levels of $G$ and $T$ bases in the Heavy strand somehow predispose it to PCR inhibiting damage. An alternative explanation could be the different patterning of C's in the Light strand, and of C's in the Heavy strand (Figure 1). The Light strand has 45 out to 107 cytosines $(42.1 \%)$ in singletons, being the rest clustered from 2 to 12 (clusters of $\mathrm{N}=3 \mathrm{C}$ 's in positions 16054 -
056, 16071-073, 16259-261, 16266-268, 16290-292, 16294-296, 16353-355; of $\mathrm{N}=4$ or $5 \mathrm{C}$ 's in $16362-366$ or 16363-366, depending on the Neandertal; of $N=6 C^{\prime}$ 's in $16375-380$, and of $N=11$ or $12 \mathrm{C}^{\prime}$ s, depending on the Neandertal, in positions $16182-193$ or $16183-193)$. In contrast, the Heavy strand has 27 out to 31 cytosines $(87.1 \%)$ in singletons, with only two clusters of 2 cytosines (in positions 16273-274 and 16369-370). Thus, it could be that the presence of more than one cytosine increases the chances of these being damaged. A possible mechanism to explain this could be an increased $G$ depurination (i.e. the hydrolysis of $\mathrm{G}$ from the deoxyribose-phosphate DNA backbone) rate in the opposite DNA strand when contiguous purines are present. The G depurination would create a nick exposing the C complementary nucleotide that could then be preferentially deaminated [8].

Significant differences between observed and expected frequencies are found with regards to the existence of specific hotspots within the Neandertal HVS1 region $\left(\chi_{7}^{2}=673.16\right.$, p-value $=0.000)$, with the largest concentration of hotspots being observed at positions 16108, 16111, 16112, 16172, 16201, 16211 (see Figure 2). Intriguingly, three of these positions $(16108,16111,16112)$ represent controversial Neandertal specific SNPs reported in the first Neandertal sequence [11], but the authenticity of which have been questioned since $[12,15]$. We note that these positions are not consistent with those reported previously, either in aDNA damage or in vivo mutation studies. The exception is np 16172 that has been observed as hypermutable in a large number of modern studies [22]. It is noteworthy that

\section{Hot-spot sites}

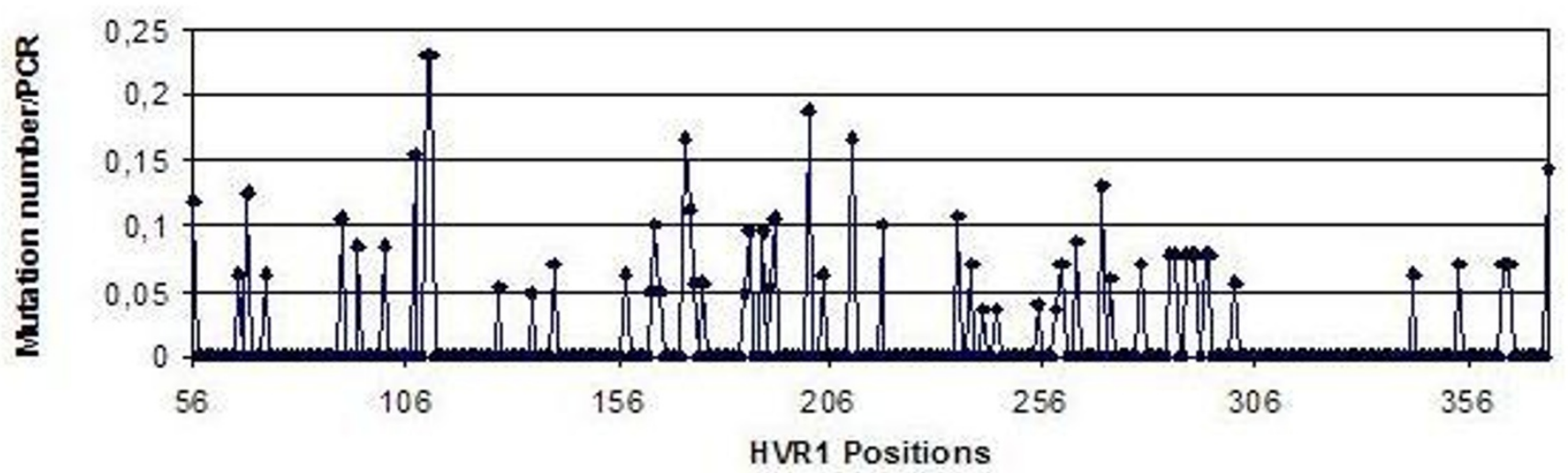

Figure 2

Distribution of hotspot positions across the Neandertal HVSI region. Hotspot strength is measured as the ratio between observed mutations and number of independent PCRs sequenced across the position 
none of these positions are placed in the 16182 (or 16183)-16193 C stretch. If our hypothesis on the C clustering is correct, it may seem that the damage in this section is underrepresented in the current published Neandertal sequences, and thus it is likely to increase in future studies. It is impossible to demonstrate the presence of hotspots in the HVS1 with the available data, as its existence may be extremely dependent on the underlying DNA sequence, with small differences in the sequence (for instance, in the presence of contiguous cytosines) manifesting large changes in hotspot distribution, but also in the number of starting template molecules in each PCR reaction, something impossible to quantify at present. However, it could be advisable to retrieve these unstable HVS1 positions at least in two independent PCRs in future studies, to prevent possible errors.

In conclusion, the possibility of comparing Neandertal PCR-generated sequence data with future sequence data derived from alternative, non-PCR based approaches (such as 454 pyrosequencing or SPEX methodology) could generate more reliable sequence data for damage analysis and could help explain the bias observed here towards $\mathrm{C} \rightarrow \mathrm{T}$ over $\mathrm{G} \rightarrow \mathrm{A}$ miscoding lesions.

\section{Authors' contributions}

OL, CL-F and EG created the Neandertal cloning database; SV and CA analyzed the data; MTPG and CL-F wrote the paper.

\section{Additional material}

\section{Additional file 1}

Distribution of consistent mutations in each Neandertal's mtDNA. Original distribution of mutations (only consistent substitutions) and examined PCRs for each mtDNA position between 16056 and 16375.

Click here for file

[http://www.biomedcentral.com/content/supplementary/17560500-1-40-S1.doc]

\section{Additional file 2}

Summary of consistent mutations. Summarized distribution of mutations and examined PCR in a prototypal individual.

Click here for file

[http://www.biomedcentral.com/content/supplementary/1756-

0500-1-40-S2.doc]

\section{Additional file 3}

Nucleotide changes for each consistent mutation. Nucleotide changes for each consistent mutation in Neandertal's mtDNA.

Click here for file

[http://www.biomedcentral.com/content/supplementary/17560500-1-40-S3.xls]

\section{Additional file 4}

Statistics used for estimating the damage distribution. Calculation of the expected probability of multiple (consistent) mutations per region in the mtDNA hypervariable region 1.

Click here for file

[http://www.biomedcentral.com/content/supplementary/1756-

0500-1-40-S4.doc]

\section{Acknowledgements}

We are grateful to Adrian Briggs (Max Planck Institute, Leipzig) for helpful suggestions. This research has been supported by a grant (CGL200603987) from the Spanish Ministry of Education and Science to C.L.-F. and S.V. E.G has a PhD fellowship from the Spanish Ministry of Education and Science.

\section{References}

I. Pääbo S, Poinar H, Serre D, Jaenicke-Despres V, Hebler J, Rohland N, Kuch M, Krause J, Vigilant L, Hofreiter M: Genetic analyses from ancient DNA. Annu Rev Genet 2004, 38:645-679.

2. Pääbo S: Ancient DNA: extraction, characterization, molecular cloning, and enzymatic amplification. Proc Natl Acad Sci USA 1989, 86(6): 1939-1943.

3. Hofreiter M, Jaenicke V, Serre D, Haeseler Av A, Pääbo S: DNA sequences from multiple amplifications reveal artifacts induced by cytosine deamination in ancient DNA. Nucleic Acids Res 200I, 29(23):4793-4799.

4. Gilbert MT, Willerslev E, Hansen AJ, Barnes I, Rudbeck L, Lynnerup $\mathrm{N}$, Cooper $\mathrm{A}$ : Distribution patterns of postmortem damage in human mitochondrial DNA. Am J Hum Genet 2003, 72:32-47.

5. Binladen J, Wiuf C, Gilbert MTP, Bunce M, Barnett R, Larson G, Greenwood AD, Haile J, Ho SY, Hansen AJ, Willerslev E: Assessing the fidelity of ancient DNA sequences amplified from nuclear genes. Genetics 2006, I72(2):733-74I. Epub 2005 Nov 19

6. Stiller M, Green RE, Ronan M, Simons JF, Du L, He W, Egholm M, Rothberg JM, Keates SG, Ovodov ND, Antipina EE, Baryshnikov GF, Kuzmin YV, Vasilevski AA, Wuenschell GE, Termini J, Hofreiter M, Jaenicke-Després V, Pääbo S: Patterns of nucleotide misincorporations during enzymatic amplification and direct large-scale sequencing of ancient DNA. Proc Natl Acad Sci USA 2006, 103(40): I3578-13584.

7. Gilbert MT, Binladen J, Miller W, Wiuf C, Willerslev E, Poinar H, Carlson JE, Leebens-Mack JH, Schuster SC: Recharacterization of ancient DNA miscoding lesions: insights in the era of sequencing-by-synthesis. Nucleic Acids Res 2007, 35(I): I- I0.

8. Briggs AW, Stenzel U, Johnson PLF, Green RE, Kelso J, Prüfer K, Meyer M, Krause J, Ronan MT, Lachmann M, Pääbo S: Patterns of damage in genomic DNA sequences from a Neandertal. Proc Natl Acad Sci USA 2007, 104:14616-14621.

9. Brotherton P, Endicott P, Sanchez JJ, Beaumont M, Barnett R, Austin J, Cooper A: Novel high-resolution characterization of ancient DNA reveals C > U-type base modification events as the sole cause of post mortem miscoding lesions. Nucleic Acids Res 2007, 35:5717-5728.

10. Pääbo S, Irwin DM, Wilson AC: DNA damage promotes jumping between templates during enzymatic amplification. I Biol Chem 1990, 265(8):47|8-472I.

II. Krings M, Stone A, Schmitz R, Krainitzki H, Stoneking M, Pääbo S: Neanderthal DNA sequences and the origin of modern humans. Cell 1997, 9:19-30.

12. Schmitz RW, Serre D, Bonani G, Feine S, Hillgruber F, Krainitzki H, Pääbo S, Smith FH: The Neandertal type site revisited; interdisciplinary investigations of skeletal remains from the Neander Valley, Germany. Proc Natl Acad Sci USA 2002, 99:13342-13347.

13. Ovchinnikov IV, Götherström A, Romanova GP, Kharitonov VM, Lidén K, Goodwin W: Molecular analysis of Neandertal DNA from the northern Caucasus. Nature 2000, 404:490-493.

14. Serre D, Langaney A, Chech M, Teschler-Nicola M, Paunovic M, Mennecier P, Hofreiter M, Possnert G, Pääbo S: No evidence of Nean- 
dertal mtDNA contribution to early modern humans. PLoS Biol 2004, 2:E57.

15. Caramelli D, Lalueza-Fox C, Condemi S, Longo L, Milani L, Manfredini A, de Saint Pierre M, Adoni F, Lari M, Giunti P, Ricci S, Casoli A, Calafell F, Mallegni F, Bertranpetit J, Stanyon R, Bertorelle G, Barbujani G: A highly divergent mtDNA sequence in a Neandertal individual from Italy. Curr Biol 2006, 16:R630-R632.

16. Lalueza-Fox C, Krause J, Caramelli D, Catalano G, Milani L, Sampietro ML, Calafell F, Martínez-Maza C, Bastir M, García-Tabernero A, de la Rasilla M, Fortea J, Pääbo S, Bertranpetit J, Rosas A: Mitochondrial DNA of an Iberian Neandertal suggests a population affinity with other European Neandertals. Curr Biol 2006, 16:R629-R630.

17. Krause J, Orlando L, Serre D, Viola B, Prüfer K, Richards MP, Hublin J], Hänni C, Derevianko AP, Pääbo S: Neandertals in Central Asia and Siberia. Nature 2007, 444:902-904.

18. Anderson S, Bankier AT, Barrell BG, de Bruijn MH, Coulson AR, Drouin J, Eperon IC, Nierlich DP, Roe BA, Sanger F, Schreier PH, Smith AJ, Staden R, Young IG: Sequence and organization of the human mitochondrial genome. Nature 198I, 290:457-465.

19. Gilbert MT, Hansen AJ, Willerslev E, Rudbeck L, Barnes I, Lynnerup $\mathrm{N}$, Cooper A: Characterization of genetic miscoding lesions caused by postmortem damage. Am J Hum Genet 2003, 72:48-6I.

20. Gilbert MTP, Shapiro BA, Drummond A, Cooper A: Post mortem DNA damage hotspots in Bison (Bison bison and $B$. bonasus) provide supporting evidence for mutational hotspots in human mitochondria. J Archaeol Sci 2005, 32:1053-1060.

21. Hansen A, Willerslev E, Wiuf C, Mourier T, Arctander P: Statistical evidence for miscoding lesions in ancient DNA templates. Mol Biol Evol 200I, 18:262-265.

22. Gilbert MTP: Post mortem damage of mitochondrial DNA. In Human Mitochondrial DNA and the Evolution of Homo sapiens Edited by: Bandelt HJ, Macaulay V, Richards M. Heidelberg: Springer-Verlag; 2006.

Publish with Bio Med Central and every scientist can read your work free of charge

"BioMed Central will be the most significant development for disseminating the results of biomedical research in our lifetime. "

Sir Paul Nurse, Cancer Research UK

Your research papers will be:

- available free of charge to the entire biomedical community

- peer reviewed and published immediately upon acceptance

- cited in PubMed and archived on PubMed Central

- yours - you keep the copyright
BioMedcentral 